\title{
Long-Term Visual Outcome Following Cataract Surgery Using Intraocular Lens - A Community-Based Cross-Sectional Study
}

\author{
S. Priyadharshini \\ Department of Community Medicine, Sri Ramachandra Medical College Hospital and Research Institute, \\ Porur, Chennai, Tamil Nadu, India
}

Received July 9, 2021; Revised October 13, 2021; Accepted November 11, 2021

\section{Cite This Paper in the following Citation Styles}

(a): [1] S. Priyadharshini , "Long-Term Visual Outcome Following Cataract Surgery Using Intraocular Lens - A Community-Based Cross-Sectional Study," Universal Journal of Public Health, Vol. 9, No. 6, pp. 360 - 366, 2021. DOI: 10.13189/ujph.2021.090602.

(b): S. Priyadharshini (2021). Long-Term Visual Outcome Following Cataract Surgery Using Intraocular Lens - A Community-Based Cross-Sectional Study. Universal Journal of Public Health, 9(6), 360 - 366. DOI: 10.13189/ujph.2021.090602.

Copyright $\bigcirc 2021$ by authors, all rights reserved. Authors agree that this article remains permanently open access under the terms of the Creative Commons Attribution License 4.0 International License

\begin{abstract}
Purpose: Long-term follow up and determination of visual acuity in the community is seldom carried out to examine the outcome of medical intervention, but the same is routinely assessed after cataract surgery [short-term] in medical camps and hospitals. Setting: Rural areas in Chidambaram town, Cuddalore district, Tamil Nadu, South India. Design: Cross-sectional study. Methods: All patients who underwent cataract surgery with intraocular lens (IOL) implantation were included in this study. With a $5.4 \%$ prevalence of cataract operated cases in the community, 95\% confidence limit and 5\% absolute precision, sample size was calculated as eighty-two. Door-to-door survey was conducted to obtain the sample. Data was collected using proforma and visual acuity was assessed using Snellen's chart. Data analysis was done using Statistical Package for Social Sciences (SPSS) software version 18. Chi-square test was used to assess the association between different parameters and determine the visual acuity status. The obtained $\mathrm{p}$ value of $<0.05$ was considered significant. Results: Uncorrected, present visual acuity in the first cataract-operated eye, 53 [64.6\%], 25[30.5\%] and 4 [4.9\%] of operated eyes had poor vision, near normal vision and normal vision, respectively whereas it was $14[31.2 \%], 29$ [64.4\%] and 2 $[4.4 \%]$ in the second. Long-term subjective visual outcome was reported to be good in the postoperative period in 51[62.2\%] of cases. Conclusion: In the course of the
\end{abstract}

long-term follow up, it is revealed that a majority of the operated cases have near normal or poor vision [uncorrected]. Vision can be improved by the simple correction of refractive error.

Keywords Cataract Surgery, Long-Term Follow Up, Community-Based, IOL

\section{Synopsis}

A majority of cataract operated eyes are noted to have either near normal or poor vision [uncorrected] in their operated eyes during their long-term follow up, the latter effectively addressed by simple correction of the underlying refractive error to improve vision.

\section{Introduction}

Cataract remains the most common cause for preventable blindness not only in India but also all over the world [1]. It has been estimated that about half of all cases of blindness in developing countries like India are due to cataract [2]. It is predicted that in the future, every year, about three million people will develop visual 
disability that could be attributed to cataracts [3]. Extra-capsular cataract extraction with implantation of intraocular lens in the posterior chamber [PCIOL] is the commonly practiced surgical procedure for the management of cataract [4]. Though this effective and inexpensive surgical procedure holds the distinction of being the most commonly preferred ophthalmic surgery at a global level, the surgical outcome of the same remains a challenge.

PCIOL, when performed by a skilled ophthalmologist, offers good vision [best-corrected visual acuity of 6/12 or better] to $90 \%$ of the patients [5] and an equal proportion of patients are generally satisfied with their surgical outcome [6]. The surgical outcome can be significantly improved in a greater number of patients by increasing the number of trained ophthalmologists and developing top-notch infrastructure in terms of availability of advanced equipments, measures that could help to address both issues [7]. However, the success rate of the surgery also depends on monitoring the quality of the surgery. Visual acuity following the surgical procedure has been traditionally done during the immediate postoperative period [before discharge] and during the follow-up consultations in the subsequent months because wound healing can change refractive power and resolution of corneal edema can eventually improves the visual acuity. Rarely, declaim in the visual acuity is also reported.

In developing countries like India, postoperative follow-up rates are very low [usually about 20\%] [8], due to difficulties in transportation, the costs factor and lack of awareness about the benefits of follow-up visits [9]. World Health Organization [WHO] [10] recommends that post-surgery more than $80 \%$ of operated cases should have uncorrected [without refraction] visual acuity of 6/18 or better in the operated eye but does not state specific time frame during which the visual acuity is supposed to be mentioned following surgery.

Success rate of surgery is one of the commonly used indicators to measure the surgical outcome. It refers to the proportion of surgeries that result in restoration of sight in the operated eye in a particular year [11]. Several research studies available in literatures have shown highly varying success rates ranging from $28 \%$ to $92 \%[12,13]$. This huge discrepancy in the success rates could be attributed to the place where the surgery and study were conducted, medical camp settings or hospital settings precincts [13, 14]. This significant difference in the success rate has resulted in lack of clarity about the need for the primary care physician to refer the patient to an ophthalmologist. Long-term follow up and determination of visual acuity in the community set up could be a better option to overcome this bias. To the best of the author's knowledge, there are only a limited number of research studies available in literatures that have investigated the long-term surgical outcome following implantation of IOL surgery. Hence, it is envisaged that this study will address the identified research gap by assessing the long-term follow up after implantation of IOL in the selected study area of South Indian community, which could help the primary care physician to gain a better understanding better the outcome of IOL surgery.

\section{Research Methodology}

This community-based cross-sectional study was conducted in Chidambaram by the Department of Community Medicine which offers healthcare services and conducts outreach programmes in rural, remote and medically underserved areas. All patients who underwent cataract surgery with IOL implantation were included in the study. Patients whose operative history was not known were excluded from the study. With a prevalence of $5.4 \%$ of the cataract operated cases in the community, 95\% confidence limit and 5\% absolute precision, sample size was calculated as eighty-two. Since this investigation was planned as a community-based study, door-to-door survey was conducted to check the cataract surgery status and only cases with positive history of IOL surgery were included in the study. This survey was undertaken for a period of five months from April to August during which the calculated sample size was achieved from the community.

The principal investigator explained the purpose of the study to each participant and written consent was obtained prior to the commencement of the study. Data collection was done using a proforma with questions related to ocular surgery. The current visual acuity of the patients was assessed using Snellen's chart. This study was registered with Institutional Human Ethics Committee (IHEC). Data analysis was done using SPSS version 18. Chi square test was done to assess the association between different parameters and visual acuity status. The $p$ value of $<0.05$ was considered as significant.

\section{Results of the Study}

Out of 632 participants interviewed through door-to-door survey method, 82[13\%] had undergone intraocular lens surgery in the past for the treatment of cataract whereas 550 [87\%] did not have the surgery. The participants who underwent IOL surgery were included in the analysis and interviewed. Among the participants who underwent surgery for cataract the majority belonged to the age group of $60-74$ years - 59[72\%], followed by 45-59 years - 16[19.5\%] and a few more than 75 years 7[8.5\%]. There were more females- 52[63.4\%] and homemakers- 41[50\%], in this study. Based on economic dependency, there were 55 [67.1\%] participants who were economically dependent and a majority of them 31[58.5\%] lived in nuclear type of family. The demographic characteristics of the study participants who underwent 
IOL surgery for treatment of cataract is shown in Table 1.

Table 1. Demographic characteristics of participants who underwent IOL surgery

\begin{tabular}{|c|c|c|}
\hline Variables & Frequency & Percentage \\
\hline \multicolumn{3}{|c|}{ Age group } \\
\hline 45-59 years & 16 & 19.5 \\
\hline $60-74$ years & 59 & 72.0 \\
\hline$>75$ years & 7 & 8.5 \\
\hline \multicolumn{3}{|c|}{ Gender } \\
\hline Males & 30 & 36.6 \\
\hline Females & 52 & 63.4 \\
\hline \multicolumn{3}{|c|}{ Occupation } \\
\hline Home makers & 41 & 50.0 \\
\hline Daily wages & 32 & 39.0 \\
\hline Shop keepers & 9 & 11.0 \\
\hline \multicolumn{3}{|c|}{ Economic dependency } \\
\hline Independent & 27 & 32.9 \\
\hline Dependent & 55 & 67.1 \\
\hline \multicolumn{3}{|c|}{ Type of family } \\
\hline Nuclear & 31 & 58.5 \\
\hline Joint & 34 & 41.5 \\
\hline
\end{tabular}

On assessing the uncorrected, present visual acuity in the first operated eye, it was observed that 53[64.6\%], $25[30.5 \%]$ and $4[4.9 \%]$ of operated eyes had poor vision, near normal vision and normal vision, respectively. Duration of time since the surgery on the first eye was reported as less than one year, one-five years and more than five years in 21[25.6\%], 32[39\%] and 29[35.4\%] of cases, respectively. In the second operated eye, uncorrected present visual acuity was reported and 14[31.2\%], 29[64.4\%] and 2[4.4\%] of operated eyes had poor vision, near normal vision and normal vision, respectively. Duration of time since the surgery on the second eye was reported as less than one year, one-five years and more than five years in $11[24.4 \%], 21[46.6 \%]$ and 13 [29\%] of cases, respectively [Table 2].

Long-term subjective visual outcome was reported as good in the postoperative period in 51[62.2\%] of cases whereas 31 [37.8\%] of operated cases were seen to have relatively worsening of vision over a period of time. The proportion of cases with different surgery related parameters is shown in Table 3 .
Table 2. Present Visual acuity and duration before which IOL surgery done

\begin{tabular}{|c|c|c|}
\hline Variables & $\begin{array}{c}\text { First operated } \\
\text { eye } N(\%) \\
\text { N= } 82\end{array}$ & $\begin{array}{c}\text { Second } \\
\text { operated eye } \mathrm{N} \\
(\%) \\
\mathrm{N}=45 \\
\end{array}$ \\
\hline \multicolumn{3}{|c|}{ Present visual acuity in first operated eye } \\
\hline $\begin{array}{c}\text { Poor vision } \\
\text { (6/24-3/60-unable to } \\
\text { appreciate hand movements) }\end{array}$ & $53(64.6)$ & $14(31.2)$ \\
\hline $\begin{array}{l}\text { Near normal vision } \\
(6 / 18-6 / 12)\end{array}$ & 25 (30.5) & $29(64.4)$ \\
\hline Normal vision (6/9-6/6) & $4(4.9)$ & $2(4.4)$ \\
\hline \multicolumn{3}{|c|}{ Duration before which surgery done } \\
\hline$<1$ year & $21(25.6)$ & $11(24.4)$ \\
\hline $1-5$ years & $32(39)$ & $21(46.6)$ \\
\hline$>5$ years & $29(35.4)$ & $13(29)$ \\
\hline
\end{tabular}

Table 3. Surgery related parameters

\begin{tabular}{|c|c|c|}
\hline Variables & Frequency & Percentage \\
\hline IOL surgery done in & 37 & 45.1 \\
\hline Single eye & 45 & 54.9 \\
\hline Both eyes & 64 & 78.0 \\
\hline \multicolumn{3}{|c|}{ Place of Surgery } \\
\hline Institution & 18 & 22.0 \\
\hline Private hospital & 16 & 19.5 \\
\hline \multicolumn{2}{|c|}{ Duration of stay in hospital } \\
\hline \multicolumn{2}{|c|}{60.5} \\
\hline 3-5 days & 66 & 10.97 \\
\hline \multicolumn{2}{|c|}{ Immediate post-surgical complications } \\
\hline Present & 9 & 89.03 \\
\hline Absent & 73 & 62.19 \\
\hline \multicolumn{2}{|c|}{ Subjective visual outcome - long term } \\
\hline Good as post operative & 51 & 37.81 \\
\hline $\begin{array}{c}\text { Relative worsening over } \\
\text { a period of time }\end{array}$ & 31 & \\
\hline
\end{tabular}

In assessing the association between various parameters and present visual outcome status, factors like age group, duration of time since the surgery, complications and place of surgery were found to be significantly associated with visual outcome whereas gender and associated chronic illnesses were found to have no significant influence on the visual outcome [Table 4]. 
Table 4. Association between various parameters and visual outcome

\begin{tabular}{|c|c|c|c|c|c|}
\hline \multirow{2}{*}{ Variables } & \multicolumn{3}{|c|}{ Visual out come } & \multirow{2}{*}{ Chi square value } & \multirow{2}{*}{$P$ value } \\
\hline & Normal (\%) & Near normal (\%) & Poor (\%) & & \\
\hline \multicolumn{6}{|c|}{ Age group } \\
\hline $45-59$ years & $3(18.8)$ & $5(31.3)$ & $8(50.0)$ & \multirow{2}{*}{5.33} & \multirow{2}{*}{$0.07 *$} \\
\hline$\geq 60$ years & $1(1.5)$ & $20(30.30)$ & $45(68.18)$ & & \\
\hline \multicolumn{6}{|c|}{ Sex } \\
\hline Male & $1(3.3)$ & $11(36.7)$ & $18(60)$ & \multirow{2}{*}{0.444} & \multirow{2}{*}{0.505} \\
\hline Female & $3(5.8)$ & $14(26.9)$ & $35(67.3)$ & & \\
\hline \multicolumn{6}{|c|}{ Duration before which surgery was done } \\
\hline$<1$ year & $2(9.5)$ & $13(61.9)$ & $6(28.6)$ & \multirow{3}{*}{16.84} & \multirow{3}{*}{$<0.001^{*}$} \\
\hline $1-5$ years & $1(3.1)$ & $8(25)$ & $23(71.9)$ & & \\
\hline$>5$ years & $1(3.4)$ & $4(13.8)$ & $24(82.8$ & & \\
\hline \multicolumn{6}{|c|}{ Complications } \\
\hline Present & 0 & 0 & $9(100)$ & \multirow{2}{*}{5.53} & \multirow{2}{*}{$0.019 *$} \\
\hline Absent & $4(5.5)$ & $25(34.2)$ & $44(60.3)$ & & \\
\hline \multicolumn{6}{|c|}{ Chronic diseases } \\
\hline Present & 0 & 13 (41.9) & 18 (58.1) & \multirow{2}{*}{0.941} & \multirow{2}{*}{0.332} \\
\hline Absent & $4(7.8)$ & $12(23.5)$ & 35 (68.6) & & \\
\hline \multicolumn{6}{|c|}{ Place of Surgery } \\
\hline Institution & $2(3.1)$ & 17 (26.6) & 45 (70.3) & 4.11 & $0.043^{*}$ \\
\hline Private hospital & $2(11.2)$ & $8(44.4)$ & $8(44.5)$ & & \\
\hline
\end{tabular}

*Significant

\section{Discussion}

India is a rapidly, developing country that aims to offer citizens a comprehensive public health care delivery system, in the best possible way. Apart from the governmental agencies, the non-governmental organizations [NGO] play a major role in providing essential health care, especially ophthalmic care. Screening for cataract is being done by conducting eye care camps on a periodical basis to benefit local communities, and patients identified as requiring surgical intervention are referred to nearby ophthalmic centers where cataract surgeries are done at either low cost or entirely free of cost. Despite these community eye care promotion measures, the proportion of people with poor vision continues to remain high. In addition, patients who have had a cataract operation with intraocular lens, complain about poor vision, not immediately after surgery but in the long term.

Over the last decade, there have only been minimal community-based studies on the long-term visual outcome following cataract surgery. In the present study, a majority of the participants comprised of the dependent population of above 60 years with little or no formal education and most of them were females. The patients did not know the importance of appropriate treatment or how to access timely medical care. The main barrier encountered was an unwillingness to pay for surgery. Yet another obstacle was a marked reluctance among the elderly to undergo surgery and ensure periodic follow up eye check-ups. This was attributed to a lack of awareness that cataracts can be fully cured with timely intervention but could lead to blindness if left untreated.

In a study conducted in Hyderabad city [15], 21.4\% of the postoperative eyes had a presenting visual acuity of less than 6/60 whereas the study conducted in the state of Karnataka [16] reported 26.4\%. In another study conducted in Karnataka [17], only $12.5 \%$ of the bad outcomes were thought to be due to refractive error. However, vastly different results were obtained from studies conducted in developed countries. A study carried out in Australia [18], reported that $89 \%$ of the eyes operated for cataract had a corrected vision of $6 / 18$ or better and the UK National Cataract Survey [19] revealed that $87 \%$ of the operated eyes had $6 / 12$ or better vision at final refraction.

Limburg et al. [20] conducted a study and reported following cataract surgery in all the cases. Visual acuity tended to improve over time. They highlighted the fact that at eight weeks or more follow up, surgical complications or inadequate spectacle correction accounted for $72 \%$ of the causes of poor outcome. They also pointed out the significant reduction in complication rates over the course of the six months of follow up period. 
Reidy et al. [21] observed that $92 \%$ of the patients had visual acuity of $6 / 18$ or better one year after surgery. The authors stated that the surgical outcomes for cases operated in eye camps and hospitals were almost similar. Hennig et al. [22] performed a study and noted that uncorrected visual acuity at discharge was $6 / 18$ or better in $76.8 \%$ of the operated eyes but it declined to $70.5 \%, 6$ weeks after the surgery and $64.9 \%$ after a follow up period of one year. Corrected visual acuity was $6 / 18$ or better in $96.2 \%$ of the operated eyes at six weeks post-surgery and in $95.9 \%$ after one year. Poor visual outcome was reported in $<2 \%$ of the operated eyes.

From their study, Salahuddin et al. [23] noted that average age of the patients undergoing cataract operation was 57 years with $64.7 \%$ being female and $35.3 \%$ being male. The preoperative diagnostic test showed that $79.4 \%$ of the patients had poor vision compared to only $1.4 \%$ patients who continued to have poor vision even after the operation. A corrected vision of $6 / 18$ or better was achieved in $87.9 \%$ of the operated eyes whereas uncorrected vision of $6 / 18$ or better was obtained in $72.3 \%$, as noted at the last follow up visit. Also, the authors noted that $4.2 \%$ of the patients had a poor visual outcome. Following their study, Harpreet et al. [24] reported that after surgery and at the time of discharge with standard aphakic spherical spectacles, $11.3 \%$ of the patients had visual acuity of less than $6 / 60$ and $25.9 \%$ had an acuity of $6 / 18$ or better. During follow-up examination six weeks after surgery, $61.2 \%$ were seen to have the best correction, $4.3 \%$ had a poor outcome and the rest of the cases had visual acuity of $6 / 18$ or better.

In a study conducted by Salahuddin et al. [25], the authors stated that uncorrected vision of 6/18 or better was obtained in $72.3 \%$ of the operated eyes at their last follow-up visit with $>95 \%$ of the patients were satisfied with their visual outcome, when assessed subjectively. Pokharel et al. [26] conducted a study and reported that $15 \%$ of the operated eyes had presenting visual acuity $>6 / 18$ in both eyes, and $38 \%$ had the best corrected visual acuity. In their study, it was found that $21 \%$ were still blind with visual acuity $<6 / 60$ in both eyes, while $7 \%$ had the best correction.

Yorston et al. [27] undertook a study and noted that visual acuity of $6 / 18$ or better was obtained in $94.3 \%$ and in $78.2 \%$ of the operated eyes with corrected and uncorrected vision, respectively. Limberg et al. [14] conducted cross-sectional population-based study and reported that the outcome was good in $43.5 \%$ and poor in $26.4 \%$. Lalit et al. [28] reported that post-operatively, $44.1 \%$ had visual acuity better than $6 / 18$ and $84.1 \%$ of the patients had visual acuity better than 3/60 after six weeks.

In the study conducted by Murthy et al. [29], it was observed that $44.7 \%$ of the operated eyes obtained a good vision while $39.9 \%$ had low vision. Suraj et al. [30] tested the vision of patients six weeks after their operation and pointed out that $9.5 \%$ of the patients had poor visual outcome without any correction. Matta et al. [31] conducted a study and reported that after 12 weeks of surgery, $61.8 \%$ had a good outcome. Based on best-corrected visual acuity, $91.7 \%$ had a good outcome. Murthy et al. [32] stated that $44.1 \%$ of the patients initially had visual acuity $<6 / 60$ and $31.5 \% \geq 6 / 18$, with best correction the figures were $14.0 \%$ and $61.5 \%$, respectively. Sen [33] reported that $85 \%$ of the cataract patients in Chhatarpur district,Madhya pradesh had visual acuity $\geq 6 / 18$ at 6weeks and 90\% reported "good" outcome. The author based his study on the feedback obtained from patients whom he contacted over the telephone six years after their cataract surgery. Anand et al. [34] conducted a study of three hundred cataract patients in rural Punjab. The authors reported that $16.82 \%$ were blind, $37.9 \%$ had low visual acuity and $45.3 \%$ of the patients gained good visual acuity following PCIOL.

\section{Conclusion}

The comprehensive literature survey indicates that a majority of the patients who underwent cataract operation had near-normal vision while a few were noted to have poor vision [uncorrected] during their long-term follow up. Long-term subjective visual outcome was reported to be the same as that in the postoperative period in only about $60 \%$ of the cases, whereas the rest of the cases reported relatively low or worsening of vision over a period of time. In assessing the association between various parameters and present visual outcome status, it was found that age category, duration of time since the surgery on the first eye and second eye, post-surgery complications and place of surgery were factors that had a significant influence on the long-term visual outcome. The vision of the patients who have undergone the cataract operation can be easily improved with minimal expenditure by simple correction of refractive error, which can be addressed by the primary care physician. This clearly shows that there is a critical need to track and follow up on the operated cases on long-term basis either by the physician who did the operation or by the primary care physician. Further, periodical awareness programmes must be held for senior citizens to sensitize them to the need for annual eye exam to monitor eye health, early cataract treatment and regular postoperative follow up visits to the ophthalmologist to maintain good vision for a lifetime eye health.

\section{Value Statement}

\section{What was known:}

- Success rate of the cataract surgery [no. of surgeries] is one of the commonly used indicators to measure the surgical outcome. 
- Extra-capsular cataract extraction with implantation of intraocular lens in the posterior chamber [PCIOL] is the commonly practiced effective and in expensive surgical procedure for the management of cataract.

- Visual acuity following the surgical procedure has been traditionally done during the immediate postoperative period [before discharge] and during the follow up visits [subsequent months]. In developing countries like India, postoperative follow-up rates are generally very low [usually about 20\%][8], due to difficulties in transportation, costs and lack of awareness of the importance of follow-up visits[9].

\section{What this paper adds:}

- Long-term subjective visual outcome is observed to be the same as that in the postoperative period in only about $60 \%$ of the cases whereas the rest of the cases are seen to have relatively low or worsening of vision over a period of time.

- The population, especially those who have undergone the cataract surgery, must be educated as to the need for periodic follow ups, which can be easily addressed by the primary care physician [from whom a majority of the Indian population seeks medical care] by simple correction of refractive error or timely appropriate referral steps.

\section{Acknowledgement}

The author would like to express her sincere gratitude to Dr. N. Ethirajan., Professor and Dr. P. K. Govindarajan., Professor for readily sharing their expertise as well as for their constant encouragement and unstinting support which have made this research work possible. I extend my sincere thanks to R. Banumathi for her most valuable help during the field visits.

\section{Declarations}

\section{Funding}

No funding source.

\section{Conflict of interest}

None declared.

\section{Ethical approval}

This study is registered with Institutional Human Ethics Committee.

\section{REFERENCES}

[1] B. Thylefors,' A.-D. Negrel, R. Pararajasegaram, \& K.Y. Dadzie, "Global data on blindness" Bulletin of the World Health Organization, Vol 73, no.1, pp 115-121, 1996. PMID: 7704921

[2] Dandona L, Dandona R, Naduvilath T, "Is current eye care policy focus almost exclusively on cataract adequate to deal with blindness in India?” Lancet, Vol 351, pp 1312-1316, 1998. https://doi.org/10.1016/S0140-6736(97)09509-3

[3] Minnassian DC, Mehra V, "3.8 Million blinded by cataract each year: projections from the first epidemiological study of incidence of cataract blindness in India," $\mathrm{Br} \mathrm{J}$ Ophthalmol, Vol 74, pp 341-343, 1990. http://dx.doi.org/1 0.1136/bjo.74.6.341

[4] Gupta AK, Tewari HK, Ellwein LB, "Cataract surgery in India: results of a 1995 survey of ophthalmologists,” Indian Journal of Ophthalmology, Vol 46, no.1, pp 47-50, 1998. PMID: 9707848

[5] Zaidi FH, Corbett MC, Burton BJ, Bloom PA, "Raising the benchmark for the 21st century-the 1000 cataract operations audit and survey: outcomes, consultant-supervis ed training and sourcing NHS choice," British journal of ophthalmology, Vol 91, no. 6, pp 731-736, 2007. http://dx.doi.org/10.1136/bjo.2006.104216

[6] Lundstrom M, Stenevi U, Thorburn W, Roos P, "Catquest questionnaire for use in cataract surgery care: assessment of surgical outcomes,” J Cataract Refract Surg, Vol 24, pp 968-974, 1998. https://doi.org/10.1016/S0886-3350(98)80 053-9

[7] Huang W, Ye R, Liu B et al, "Visual outcomes of cataract surgery performed by supervised novice surgeons during training in rural China," Clin Experiment Ophthalmol, Vol 41, no.5, pp 463-470, 2012. https://doi.org/10.1111/ceo.12 021

[8] Limburg H, Foster A, Gilbert C, Johnson GJ, Kyndt M, "Routine monitoring of visual outcome of cataract surgery Part 1: Development of an instrument," British journal of ophthalmology, Vol 89 no.1, pp 45-49, 2005. http://dx.doi.org/10.1136/bjo.2004.045351

[9] Huang G, Crooms R, Chen Q, Congdon N, He M, "Compliance with follow-up after cataract surgery in rural China,” Ophthalmic Epidemiology, Vol 19, pp 67-73, 2012. https://doi.org/10.3109/09286586.2011.628777

[10] WHO, "Informal consultation on analysis of blindness prevention outcomes,” Geneva, World Health Organizatio n, 1998.

[11] Limburg H, Kumar R, Bachani D, "Monitoring and evaluating and cataract intervention in India,” $\mathrm{Br}$ Journal Ophthalmology, Vol 80, pp 951-955, 1996. http://dx.doi.org/10.1136/bjo.80.11.951

[12] Goyal M, Gupta SK, Verma L, Murthi GVS, "Socio-demographic parametersof utilization of camp based cataract surgery in rural India,” Asia Pacific Journal Ophthalmol,; Vol8, pp 15-18, 1996.

[13] Reidy A, Mehra V, Minassian D, Mahashabdc S, “Outcome of cataractsurgery in central India: A longitudinal follow up study,” Br J Ophthalmol, Vol 75, pp 102-105, 1991. 
http://dx.doi.org/10.1136/bjo.75.2.102

[14] Limburg H, Foster A, Vaidyanathan K, Murthy GVS, "Monitoring visualoutcome of cataract surgery in India", Bulletin WHO, Vol77 no.6 pp 455-460, 1999. PMID: 10427929

[15] DandonaL, Dandona R, Naduvilath, et al, "Population-based assessment of the outcome of cataract surgery in an urban population in southern India," Am J Ophthalmol, Vol 127, pp 650-658, 1999. https://doi.org/10.1016/S0002-9394(99)00044-6

[16] Limburg H, Kumar R, "Follow-up study of blindness attributed to cataract in Karnataka State, India”, Ophthalmic Epidemiology Vol 5, pp 211-223, 1998. https://doi.org/10.1076/opep.5.4.211.4193

[17] Singh AJ, Garner P, Floyd K, "Cost-effectiveness of public-funded options for cataract surgery in Mysore, India”, Lancet, Vol 355, pp 180-184, 2000. https://doi.org/10.1016/S0140-6736(99)07430-9

[18] McCarty CA, Nanjan MB, Taylor HR, “Operated and unoperated cataract in Australia," ClinExpOphthalmol Vol 28, pp77-82, 2000. https://doi.org/10.1046/j.1442-9071.20 00.00276.x

[19] Desai P, Minassian DC, Reidy A, "National cataract surgery survey 1997-8: a report of the results of the clinical outcomes”, Br J Ophthalmology, Vol 83, pp 1336-1340, 1999. http://dx.doi.org/10.1136/bjo.83.12.1336

[20] Limburg H, Foster A, Gilbert C, Johnson GJ, Kyndt M, Myatt $M$, "Routine monitoring of visual outcome of cataract surgery. Part 2: Results from eight study centres," British Journal of Ophthalmology, Vol89, no.1, pp 50-52, 2005. http://dx.doi.org/10.1136/bjo.2004.045369

[21] Reidy A, Mehra V, Minassian D, Mahashabde S, “Outcome of cataract surgery in central India: a longitudinal follow-up study,” British journal of ophthalmology,Vol75, no.2, pp 102-105, 1991. http://dx.doi.org/10.1136/bjo.75.2.102

[22] Hennig A, Kumar J, Yorston D, Foster A, “Sutureless cataract surgery with nucleus extraction: outcome of a prospective study in Nepal”, British journal of ophthalmology, Vol87, no.3, pp 266-270, 2003. http://dx.doi.org/10.1136/bjo.87.3.266

[23] Ahmad S, "Visual outcome of cataract surgery in a field hospital of sub-Saharan Africa.”, Pakistan Armed Forces Medical Journal, Vol61, no.2, pp 241-5, 2011.

[24] Kapoor H, Chatterjee A, Daniel R, Foster A, "Evaluation of visual outcome of cataract surgery in an Indian eye camp," British journal of ophthalmology, Vol83, no.3, pp 343-346, 1999. http://dx.doi.org/10.1136/bjo.83.3.343

[25] Ahmad S, Shoaib KK, Fayyaz M, Janjua TA, "Positive impact of good visual outcome on the acceptance of cataract surgery in sub-Saharan African population”, Pakistan Journal of Ophthalmology, Vol26, no.3, 2010. https://doi.org/10.36351/pjo.v26i3.561

[26] Pokharel GP, Selvaraj S, Ellwein LB, "Visual functioning and quality of life outcomes among cataract operated and unoperated blind populations in Nepal”, British Journal of Ophthalmology, Vol82, no.6, pp 606-10, 1998. http://dx.doi.org/10.1136/bjo.82.6.606

[27] Yorston D, Foster A, “Audit of extracapsular cataract extraction and posterior chamber lens implantation as a routine treatment for age related cataract in east Africa", British Journal of Ophthalmology, Vol83, no.8, pp 897-901, 1999. http://dx.doi.org/10.1136/bjo.83.8.897

[28] Shri Verma L, Gupta SK, Murthy GV, Goyal M, Pant TD, "A follow-up study on visual outcome after camp-based intracapsular cataract extraction,” Tropical Medicine \& International Health, Vol1, no.3, pp 342-347, 1996. https://doi.org/10.1046/j.1365-3156.1996.d01-45.x

[29] Murthy GV, Gupta SK, Talwar D, “Assessment of cataract surgery in rural India. Visual acuity outcome," Acta ophthalmologica scandinavica, Vol74, no.1, pp 60-63, 1996.

https://doi.org/10.1111/j.1600-0420.1996.tb00684.x

[30] Senjan S, Vashist P, Malhotra S, "Outcome of Cataract Surgery from Outreach Eye Camp,” The Official Scientific Journal of Delhi Ophthalmological Society, Vol25, no.2, pp 90-94, 2015. http://dx.doi.org/10.7869/djo.85

[31] Matta S, Park J, Palamaner Subash Shantha G, Khanna RC, Rao GN, "Cataract surgery visual outcomes and associated risk factors in secondary level eye care centers of LV Prasad Eye Institute, India,” PLoS One, Vol11, no. 1, pp 1448-1453, 2016. https://doi.org/10.1371/journal.pone.014 4853

[32] Murthy GV, Ellwein LB, Gupta S, Tanikachalam K, Ray M, Dada VK, “A population-based eye survey of older adults in a rural district of Rajasthan: II. Outcomes of cataract surgery,” Br Journal Ophthalmology, Vol108, no.4, pp 686-692, 2001. https://doi.org/10.1016/S0161-6420(00)00 $579-0$

[33] Sen,Alo, "Six years after manual small incision cataract surgery-perspective from a secondary level eye hospital in rural india,” Indian Journal of Ophthalmology, Vol 69, no. 3, pp 590-593, 2021. https://dx.doi.org/10.4103\%2Fijo.IJO _1355_20

[34] Anand R, Gupta A, Ram J, Singh U, Kumar R, "Visual outcome following cataract surgery in rural Punjab", Indian journal of ophthalmology, Vol48, no. 2, pp 153, 2000. PMID: 11116515 